\title{
6 Model of Development of Coordination Abilities in Long-Term Sport Preparation in Volleyball
}

The courses of development of coordination abilities help predict potential growth of specific coordination performance in a particular sport and serve as an example for the need to model coordination preparation in volleyball. Along with increasing coordination demands in elite sport the quality, i.e. technique, skills, and coordination performance of athletes, shall have to be developed.

In sport games, where the level of coordination factors of the sport performance cannot be quantified directly in play, the course of improvement of sport mastery is assessed by means of observing the effectiveness in a game. For example, in volleyball, sport performance is assessed by means of the rate of successful actions in a game. Nowadays, there exists a well developed system of recording and statistical computer processing and assessment of the rate of effectiveness of players in game situations of an individual as well as in group activities. Today, top sport performance directly requires equilibrium and perfect acquisition of technical elements instantaneously.

Effectiveness of the coordination model of preparation can be directly assessed using the given statistics. It shows the degree of realization of the level of individual coordination abilities in motor skills, which decide on the success or failure of action of an individual or a team in a game.

In initial stages of sport preparation the performance itself will not be in the centre of attention of the coaches and players. It is necessary to use the training time in initial stages for the development of coordination abilities. Motor skills should be acquired at first in lightened, later on in standard conditions. After having acquired them, skills can be improved in more complex, hindered conditions and directly in competitive conditions in a game. The timing of increasing the coordination mastery should be so that an athlete reached best parameters in the sphere of conditioning, technique, psychic, but also coordination abilities in an optimum age.

Analysis of coordination abilities in sport games leads to their potential division (Roth, 1982; Hirtz, 1985; Schnabel, 1994) into general coordination prerequisites and special coordination abilities, i.e. those which are limiting for the given sport game. In the initial stages of sport training coaches' attention should mainly be focused on improving the level of general gross coordination; in the later stages of deepened and highly specialized sport preparation attention should mainly be on specialized coordination abilities, the level of which directly determines their possible effective application in demanding game conditions of a sport match.

It is possible to split the sport preparation in volleyball into a similar division of coordination prerequisites. A basic principle of training coordination abilities is variability of all training methods, while the principle of proceeding from general (overall gross coordination) to particular (special coordination abilities), from easier 
to more difficult, from simple to complex exercises, is observed. Selection of methods depends on a coach's creativity, and systematic, planning, goal-oriented work.

"Adaptation changes to specific loading, conditioning an increase in the level of coordination abilities, show a different time flow and that is why it is necessary to plan a specific frequency of stimuli in microcycles, inevitable length of their effect, as well as an optimum size of applied stimuli (specific training loads - their volume and intensity)" (Šimonek \& Zrubák, 1995). In order that the effect of the training is manifested on the level of development of coordination abilities, a longer period of time is needed. Experts present at least $8-10$ weeks and higher frequency of impulses in a microcycle (4 - 6-times a week). Generally speaking, it is necessary to apply 3050 training units, which will contribute to the solution of all tasks in the given sport game.

Table 6.11 schematically shows the model of development of coordination abilities in sport games in individual stages of the sport preparation.

\subsection{Characteristics of Motor Activity in Volleyball}

Contemporary top volleyball is characterized by its high level of dynamism, elasticity, economy of movement and fast changes, thus imposing high claims not only on physical preparation, coordination abilities, psychological properties but also spatial vision, fast reaction speed, anticipation, ability to accurately estimate temporal, strength and spatial characteristics of motor activity and also the level of coordination motor prerequisites.

Well-developed coordination abilities positively influence abilities of motor control also in unusual "new" situations. In volleyball, it is enormously important to systematically improve this complex and special ability. An experienced player is very often more successful while blocking or attacking than a younger player who has got a better level of explosiveness and power. The onset of power, muscle strength and direction of strength mean relatively more. Another argument from sport medics is that a player with a well-developed level of motor coordination is less prone to injuries, than a player with poor level of coordination (Schmidt \& Lee, 2011).

Rapid situational changes typical of volleyball require players to make quick and accurate assessments of the situation, as well as making fast and effective selection of motor skills for its solution. In volleyball, movement must be corrected until the very last moment, which should bring an optimum result - processing the ball, serve reception, blocking activity, field activity, but also offensive activity, upon which the opponent cannot form its own defense. 
Table 6.11: Schematic model of development of coordination abilities in sport games

\begin{tabular}{lllllll}
\hline $\begin{array}{l}\text { Model of } \\
\text { development }\end{array}$ & Volleyball & Basketball & Handball & Soccer & $\begin{array}{l}\text { Ice- } \\
\text { Hockey }\end{array}$ & Tennis \\
\hline PŠPS & Age: & Age: & Age: & Age: & $\begin{array}{l}\text { Age: } \\
\text { 6-9 }\end{array}$ & $\begin{array}{l}\text { Age: } \\
7-12 \text { years }\end{array}$ \\
\hline
\end{tabular}

Methods of training: repetitive method (mostly 6-12 repetitions in an aerobic regime, heart rate up to 90-100 pulses/min, interval of rest: until full recovery), contrast method (e.g. changing of faster and slower tempo of performing exercises), graduation method (increasing the speed of performance of movements), method of variable exercises (performing exercises under hindered/ unfavoured conditions, variability), method of gradual increasing the demand is of exercises, "freshness" method (performing exercises at the beginning of a training unit), method using complementary exercises (e.g. a combination of requirements of differentiation of the way of ball rotation with the differentiation of direction of the ball), method of special focus of an exercise (focused only on a single coordination ability), game method (with modified rules), method of performing exercises in lightened conditions (focused on technique), "firing" method (e.g. from jogging quickly react to a signal) and others.

Loading: Intensity is low, duration $10-15^{-}$

\begin{tabular}{|c|c|c|c|c|c|c|}
\hline ISŠŠ & $\begin{array}{l}\text { Age: } \\
\text { 13-14 years }\end{array}$ & $\begin{array}{l}\text { Age: } \\
\text { 9-12 years }\end{array}$ & $\begin{array}{l}\text { Age: } \\
\text { 11-14 years }\end{array}$ & $\begin{array}{l}\text { Age: } \\
10-12 \\
\text { years }\end{array}$ & $\begin{array}{l}\text { Age: } \\
10-14 \\
\text { years }\end{array}$ & $\begin{array}{l}\text { Age: } \\
\text { 13-14 years }\end{array}$ \\
\hline
\end{tabular}

Methods of training: repetitive method (smaller number of repetitions, several times a day, 4-6x weekly), method of generalized exercise (with the overall influence on several coordination abilities), method of variation of information reception (e.g. through a hindered visual analyser), method of variation of apparatuses and tools (e.g. various size of a ball), competitive method, method of strictly specified variation, fartlek ("play with speed") and many others. Loading:Intensity is medium, duration $15-25^{\circ}$

\begin{tabular}{|c|c|c|c|c|c|c|}
\hline ŠŠPS & $\begin{array}{l}\text { Age: } \\
\text { 15-17 years }\end{array}$ & $\begin{array}{l}\text { Age: } \\
\text { 13-17 years }\end{array}$ & $\begin{array}{l}\text { Age: } \\
15-19 \text { years }\end{array}$ & $\begin{array}{l}\text { Age: } \\
13-18 \\
\text { years }\end{array}$ & $\begin{array}{l}\text { Age: } \\
15-18 \\
\text { years }\end{array}$ & $\begin{array}{l}\text { Age: } \\
\text { 15-16 years }\end{array}$ \\
\hline
\end{tabular}

Methods of training: method "under fatique" (performing exercises under fatique), method of "mirror" exercises, method of irritating vestibular apparatus, method of joined effect (development of coordination abilities parallely executed with the improvement of sport technique), method of free tactical variation (realization of various tactical tasks with different teammates and opponents), ideomotoric method (perception of temporal, spatial and dynamic parameters of movement prior to performing exercises), method of executing exercises in hindered conditions, and others. Loading: Intensity is submaximum to maximum (with longer rest intervals), duration 25-30'.

Explanations: PSPS - stage of pre-sport preparation, ISSS - stage of initial sport specialization, SSPS stage of specialized sport preparation 


\subsection{Factors Limiting Sport Performance in Volleyball}

Game performance in volleyball includes highly complex reactions with a choice of a suitable response, which closely depend on the processes of reception and processing information, therefore, it is obvious that coordination abilities, as relatively lasting, generalized performance prerequisites for programming, controlling and rectifying of movements are immensely important factors of the structure of sport performance in volleyball (Tab. 6.12, 6.13, Fig. 6.5).

If we add to the $15 \%$ share of coordination abilities also a partial share of fast reaction speed abilities, we reach a rather important share (up to 30\%) of coordination abilities on the whole performance of a volleyball player. Understandably, the importance of individual coordination abilities changes with the player's postion, e.g.in a setter, a high level of kinesthetic-differentiation ability of arms is expected, while in a receiving player and defensive player there is an assumption of a faster reaction speed to the spiked ball.

Table 6.12: Share of components of movement potential on the sport performance in volleyball (Mangi, Jokl \& Dayton, 1987)

\begin{tabular}{ll}
\hline Components & Points \\
\hline Aerobic endurance & 2 \\
\hline Speed abilities & 3 \\
\hline Power abilities & 2 \\
\hline Anaerobic endurance & 2 \\
\hline Flexibility & 3 \\
\hline Coordination abilities & 3 \\
\hline
\end{tabular}

Explanations: Scale points from 1 to 4.

Table 6.13: Share of components of movement potential (conditional and coordination abilities) on the performance in volleyball (Jonath \& Krempel, 1991)

\begin{tabular}{ll}
\hline Components & Share \\
\hline Speed abilities & $15 \%$ \\
\hline Power abilities & $45 \%$ \\
\hline Endurance abilities & $10 \%$ \\
\hline Flexibility & $15 \%$ \\
\hline Coordination abilities & $15 \%$ \\
\hline
\end{tabular}




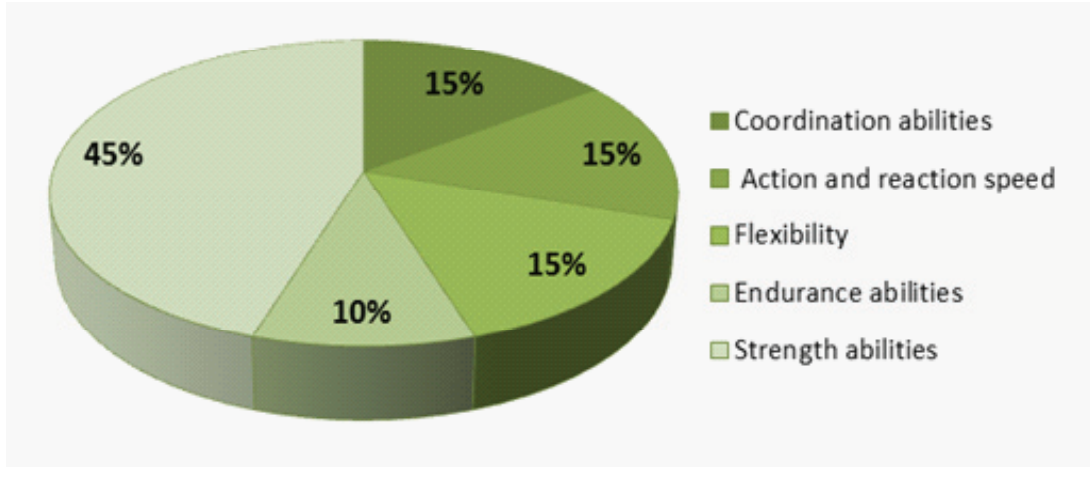

Fig. 6.5: Most important factors of structure of the sport performance in volleyball (Letzelter, 1978)

Acquisition of game activities and their further improvement and consecutive application in a game, is the task of the long-term training effort, which assumes employment of a rational selection of various training means and methods, as well as a satisfactory frequency of optimum training loads.

Research into volleyball theory and practice (Zimmermann, 1982; Dannemann, 1985) shows that the most decisive for volleyball are mostly reaction speed (specifically complex motor reaction with a choice), then kinesthetic-differentiation ability of legs (ability to estimate explosive strength) and kinesthetic-differentiation ability of arms (ability to estimate strength of ball hitting, upon passing or spiking), especially of setters.

Zimmermann (1982) specified the following ranking of coordination abilities for volleyball:

Reaction speed

Kinesthetic-differentiation

Space-orientation

Coupling and binding of movements

Motor activity rebuilding

Rhythmic ability

Balance ability
30 points

28 points

27 points

20 points

18 points

13 points

12 points

Dannemann (1985) presents importance of individual coordination abilities from the point of view of acquisition of motor skills (game activities of an individual) in Table 6.14. Let us characterize individual displays of coordination abilities in a volleyball game. Motor reaction is one of the most important abilities in volleyball. It can be defined as coordination-motoric prerequisite of a player for fast beginning and realization of effective short-term movement activities executed to an external stimulus (signal or change of situation). A volleyball player must react to stimuli of 
Table 6.14. Importance of coordination abilities from the point of view of sport-technical skills in volleyball (Dannemann, 1985)

\begin{tabular}{lllllll}
\hline \multirow{2}{*}{ Coordination ability } & \multicolumn{7}{l}{ Motor skill } & & & \\
\cline { 2 - 7 } & Serve & $\begin{array}{l}\text { Underhand } \\
\text { reception }\end{array}$ & $\begin{array}{l}\text { Overhand } \\
\text { pass }\end{array}$ & Spike & Blocking & Field play \\
\hline Raction speed & - & 3 & 1 & 1 & 3 & 3 \\
\hline Differentiation & 2 & 2 & 3 & 2 & - & 3 \\
\hline Orientation & 2 & 2 & 2 & 2 & 2 & 2 \\
\hline Coupling & 1 & 2 & 2 & 2 & 2 & 2 \\
\hline Balance & 1 & 1 & 1 & 2 & 2 & 2 \\
\hline Rebuilding & - & 2 & 1 & 2 & 1 & 2 \\
\hline Rhythmic & 1 & 1 & 1 & 1 & 1 & 1 \\
\hline
\end{tabular}

Explanations: Point scale from 1 (min. value) to 3 (max. value) according to the importance from the point of view of a sport skill

various kinds: acoustic (shout of a team-mate or opponent) or optic (sign, movement), expected (signal for serving) or unexpected ones (change of activity of a spiker from spiking into lobbing or faking). Also internal stimuli impact the coordination of a player: kinesthetic information upon ball touching through muscles, vestibular information - sense of balance, tactile information - through skin (touch). Prior to the signal, a volleyball player has got enough time for the preparation (serve reception), however, more frequently he is under a time pressure (block upon fast spike).

In volleyball simple motor or complex motor reaction are applied. Upon simple motor reaction only a part of the body is moving (only a special part of muscles is involved in the movement) and the player responds to an expected signal by a standard movement. However, in practice we often meet with a complex motor reaction when the player responds in the shortest possible time, while there exist several stimuli. Sometimes player must react to just one stimulus, which offers several possible answers and there is the need to choose the most adequate one to the given situation. The player reacts to a moving object (ball, opponent, team-mate) and attempts the fastest choice leading to a success. A ball spiked by an opponent approaches the receiving player, standing on the service line in $0.33 \mathrm{~s}$ (in female volleyball in $0.5 \mathrm{~s}$ ) and the reaction speed of trained individuals reaches about 0.35 s. Evidently, to successfully catchthe ball requires more than just fast reactions but also the ability of anticipation, i.e. presumption based on available information on the course of the play. A player's experience impacts anticipation ability in terms of detemining initial 
position of the opponent, preparatory movements, as well as overall game situation and knowledge of an opponent's habits. Specifically in volleyball, reaction speed is important mainly for:

- catching the spike (flight speed of a ball is over $100 \mathrm{~km} / \mathrm{hod}$ - Schnabel \& Thiess, 1993),

- blocking (if the opponent changes the direction of a spike suddenly),

- serve reception (speed of ball flight reaches $20 \mathrm{~m} / \mathrm{s}$ ),

- field play (fake, deflected ball from the net, block, touched ball),

- setting (sudden change of direction of the flight of the set ball, according to the reaction of blockers).

It is commonly accepted that the development of straight-line sprinting ability is important for track-and-field athletes who participate in other field- or court-based sports (e.g. soccer, American football, baseball) (Sheppard \& Young, 2006). This type of speed is developed by drills and activities that target acceleration, maximal speed, and speed endurance (Plisk, 2008). Although the ability to react quickly, rapidly accelerate is an important skill, the athlete must also be able to rapidly change direction in response to the sporting environment. All this applies also to volleyball. Agility training in volleyball includes rapid movements with the decision-making processes.

In volleyball, the ability to control movements in time and space is an inevitable coordination ability, which is externally manifested in accuracy and economy of movements in spite of time stress, defensive activity of the opponent and frequently also of fatigue. It requires conscious and perfect synchronization of movement with motor visualization. Kinesthetic differentiation in volleyball allows for:

- accurate and timed (to a certain height, zone, by a certain speed and under a cartain angle) pass from the setter to the spiker,

- $\quad$ accurate second pass through an overhead pass by the field player to the setter,

- accurate reception of the ball by the field player (underhand pass) - first pass,

- accurately placed serve,

- correctly timed jump up of the spiker upon spiking,

- correctly timed jump up of the blocker upon blocking,

- placed and timed dink, tip attack.

For a volleball player, the "feeling of ball" by hands is characteristic; mainly in a setter it represents a very important component of performance. Kinesthetic-differentiation ability plays a special role especially in the stage of improvement and stabilization of sport movements, as well as upon their application in a game activity in a match. According to some authors (Kollárovits \& Gerhát, 1993; Šimková \& Ramacsay, 1993) sensoric abilities (space-orientation and kinesthetic-differentiation ability to estimate time, space and strength) are limited also by genetic factors, however, they can be improved by the training. 
Space-orientation ability is related to the functions of analyzers (visual, acoustic, kinesthetic, tactile and vestibular) and also motor experience. It represents an ability to accurately and quickly estimate position of the body or its parts in relation to the external environment (limitation of the playground by lines, team-mates, opponent, ball, net). It allows the player to correctly orientate oneself in a game situation and coordinate movements in compliance with the particular motor task. It is employed mostly for:

- faking (faking activity) by running-in spikers (signals),

- observing and playing the ball by a setter to the best positioned spiker, or upon tip attack,

- spiking (spiker) through a "gap" in badly positioned opponent's defense (blocks),

- stopping the opponent 's offensive activity by means of a successful "positioning" of hands on a block,

- correct field layout upon serve reception and a successful reception of the ball in the field.

From the analysis of game situations in volleyball, as well as available resources (Zimmermann, 1982; Dannemann, 1985; Brandt, 1985) we suggest the following model of the structure of coordination abilities participating in the sport performance in volleyball (Fig. 6.6).

\subsection{Periodization of the Contents of Sport Preparation in Volleyball}

The system of long-term sport preparation of young talented volleyball players represents a chain of rational, coupled elements or stages of preparation, joined into one whole. It is a long-term, purposeful and optimum action at young talented players and forming their characteristic traits. Key problems in the preparation of young volleyball players is differentiation of the whole training season into individual sections or stages. Based on the long-term practical experience, as well as conclusions from research, the long-term sport preparation in volleyball can be devided into (Zeleznjak, 1988):

- $\quad$ stage of sport pre-preparation (10-12 years),

- stage of preliminary sport specialization (13-14 years),

- $\quad$ stage of deepened sport specialization (15-17 years),

- $\quad$ stage of top sport preparation (18 and over).

All the stages form a unified whole, however, each stage has certain specified tasks and objectives, related to age, level of trainability, participation in competition. In the stage of sport pre-preparation the coach is aimed at fair motivation and attracting attention of children in playing volleyball, but also regular trainings using general means in order to support health and develop his optimum psychic and somatic 


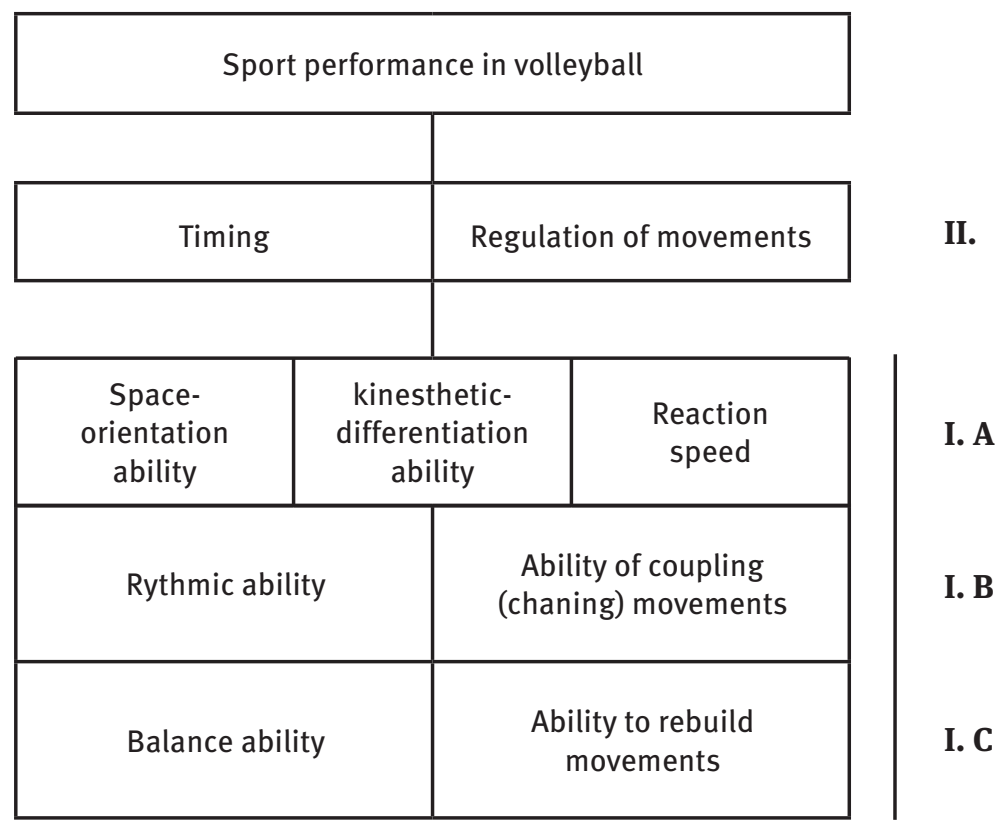

Fig. 6.6: Model of the structure of coordination abilities participating in the performance of a volleyball player. Explanations: II. - level of special coordination abilities, which directly limit sport performance in volleyball. I. A - level of general coordination abilities. I. B - coordination abilities directly limiting sport performance. I. C - coordination abilities important from the point of view of sport performance, but compensable - less important coordination abilities

growth.In the stage of preliminary sport specialization rudiments of rational sport technique and tactic, which, however, are built on the acquired platform of general preparation, begin to be acquired. In this stage, coaches should avoid a premature narrow specialization (gradually go through all offensive and defensive posts in the team) and widen as much as possible, the set of technical skills of young volleyball players. A pupil's sport age is the most important one for acquiring all abilities, which are inevitable for a successful athlete (Tab. 6.15).

At the beginning of the stage of specialized sport preparation, narrower specialization of players into posts begins along with a gradual increase in the volume and intensity of training load (often to the maximum); sport technique but also tactics are on a high level depending on the sport specialization (spiker, blocker, setter). Sport training in this stage is governed by the principles of specialized universality, increasing the load and complexity (Choutka \& Dovalil, 1991). 
Table 6.15: Share of individual kinds of sport preparation in the total volume of preparation in sport schools with the focus on volleyball (Ajrijanc \& Klešcev, 1985)

\begin{tabular}{llll}
\hline \multicolumn{3}{l}{ Stage of sport pre-preparation (10-12 years): } \\
\hline 1. & Theoretical preparation & - & $18 \mathrm{hrs}$ \\
\hline 2. & Overall physical preparation & - & $126 \mathrm{hrs}$ \\
\hline 3. & Special sport preparation & - & $65 \mathrm{hrs}$ \\
\hline 4. & Technical preparation & - & $100 \mathrm{hrs}$ \\
\hline 5. & Tactical preparation & - & $53 \mathrm{hrs}$ \\
\hline 6. & Matches & - & $34 \mathrm{hrs}$ \\
\hline 7. & Tests, control exercises & - & $20 \mathrm{hrs}$ \\
\hline
\end{tabular}

Total: 416 hours for a year of sport preparation

The process of education of top volleyball players is accomplished in the stage of top sport preparation, when athletes reach excellent results and performance on the top limit of their possibilities.

Upon solving the tasks of planning of the training process the important role is played by forecasting and modelling of sport preparation. Since Slovak volleyball players do not reach top world performance at this time, it is necessary that coaches stick to comparative attitude to model characteristics of athletes of those countries which currently play best at international level. The most problematic sphere is registration of indicators, characterizing individual factors of sport performance. Prognoses of performance development (partial models in individual stages of preparation) in volleyball shall become important predictors of the direction the training process shall follow in the nearest future.

\subsection{Methodology for the Development of Coordination Abilities in Volleyball}

Our model of coordination preparation in volleyball will consist of incorporation of coordination component (block of special exercises focused at the development of coordination abilities) into physical preparation (conditioning) in individual stages of sport preparation. The share of coordination preparation in the total volume of loading will be changing from stage to stage, as far as the amount and quality are 
concerned. Table 6.16 shows basic indicators of the training programme in the period of initial sport preparation.

In the stage of initial sport preparation children start to acquire first habits of games, initial selection continues - it is a selection of children for volleyball, a permanent

Table 6.16: Share of individual kinds of preparation in the year's cycle of the first, second and third years of sport preparation (in hours) (according to Zeleznjak, 1988)

\begin{tabular}{|c|c|c|c|c|c|c|c|c|}
\hline \multirow{3}{*}{$\begin{array}{l}\text { Kinds } \\
\text { of sport } \\
\text { preparation }\end{array}$} & \multicolumn{4}{|c|}{ 4th year of sport preparation } & \multicolumn{4}{|c|}{$6^{\text {th }}$ year of sport preparation } \\
\hline & \multirow{2}{*}{$\begin{array}{l}\text { With } \\
\text { out } \\
\text { concen } \\
\text { tration } \\
\text { training }\end{array}$} & \multicolumn{3}{|c|}{ With concentration training } & \multirow{2}{*}{$\begin{array}{l}\text { Without } \\
\text { concen } \\
\text { tration } \\
\text { training }\end{array}$} & \multicolumn{3}{|c|}{ With concentration training } \\
\hline & & $\begin{array}{l}\text { Total } \\
\text { for } \\
\text { year } 1\end{array}$ & $\begin{array}{l}\text { During the } \\
\text { school year }\end{array}$ & $\begin{array}{l}\text { At the } \\
\text { concen } \\
\text { tration } \\
\text { training }\end{array}$ & & $\begin{array}{l}\text { Total for } \\
\text { year } 1\end{array}$ & $\begin{array}{l}\text { During } \\
\text { the } \\
\text { school } \\
\text { year }\end{array}$ & $\begin{array}{l}\text { At the } \\
\text { concen } \\
\text { tration } \\
\text { training }\end{array}$ \\
\hline Theoretical & 8 & 8 & 8 & - & 14 & 14 & 14 & - \\
\hline $\begin{array}{l}\text { General } \\
\text { conditioning }\end{array}$ & 86 & 86 & 76 & 10 & 112 & 112 & 92 & 20 \\
\hline $\begin{array}{l}\text { Special } \\
\text { conditioning }\end{array}$ & 52 & 58 & 48 & 10 & 58 & 72 & 56 & 16 \\
\hline Technical & 76 & 94 & 70 & 24 & 94 & 122 & 88 & 34 \\
\hline Tactical & 26 & 30 & 22 & 8 & 48 & 54 & 44 & 10 \\
\hline Integral & 26 & 32 & 22 & 10 & 34 & 38 & 24 & 14 \\
\hline $\begin{array}{l}\text { Number of } \\
\text { competition } \\
\text { days }\end{array}$ & 12 & 15 & 12 & 3 & 20 & 20 & 16 & 4 \\
\hline Testing & 14 & 14 & 10 & 4 & 16 & 16 & 10 & 6 \\
\hline $\begin{array}{l}\text { Number of } \\
\text { training } \\
\text { hours: }\end{array}$ & 312 & 352 & 280 & 72 & 416 & 468 & 360 & 108 \\
\hline $\begin{array}{l}\text { Number of } \\
\text { training days }\end{array}$ & 144 & 161 & 128 & 33 & 188 & 196 & 164 & 32 \\
\hline $\begin{array}{l}\text { Number of } \\
\text { training } \\
\text { units }\end{array}$ & 144 & 161 & 128 & 33 & 188 & 214 & 164 & 50 \\
\hline $\begin{array}{l}\text { Number of } \\
\text { of working } \\
\text { days }\end{array}$ & 156 & 176 & 140 & 36 & 208 & 220 & 180 & 36 \\
\hline
\end{tabular}


interest in volleyball training process is developing. The place of coordination preparation can be found in three elementary spheres of sport preparation: in general (86 hours in the first and second years, and 112 in the third year of sport preparation) and specialized (52 hours in the first and second years, and 58 in the third year of sport preparation) sport preparation and in technical preparation (76 hours in the first and second years and 94 in the third year of sport preparation).

The content of general sport preparation will be exercises focused on general development of all basic coordination abilities inevitable for the later sport specialization. Part of the special sport preparation will be focused development of those coordination abilities, which are limiting for volleyball - reaction, kinestheticdifferentiation and space-orientation. Development of coordination abilities is also a part of technical improvement and therefore coaches should pay an increased attention to acquisition of correct technical elements of performing movements in the initial sport preparation. Various methods of development of coordination abilities are employed here, such as: improvement of motor skills in changed conditions, their bilateral acquisition (performing exercises on both sides - with left and right hands) In the first year of sport preparation coordination component should form more than $50 \%$ of the total time assigned for physical preparation. We shall present just a few examples of training units with various focus.

Training unit No. 1 ( $1^{\text {st }}$ year of training in a sport club): Development of reaction speed

Tasks: Development of simple motor reaction

Duration of the unit: 90 minutes

Preparatory part - 20 minutes - contents: Selection from the exercises stated below:

1. Players A and B face each other, arms bent, palms turned up, fingers are close together. Task of player A is to clap the palms of player B as quickly as possible. Player B can dodge. If player A did not hit the palm of the opponent, it becomes Player B's turn to clap.

2. Players A and B face each other in a low stance, hands on outer sides of thighs by the body. Player A tries to pull out the "gun" and "shoot" at player B, who tries to prevent player A from shooting by means of clapping on the "pistol” of player A. If player B succeed, it becomes Player B's turn to"pullthe gun".

3. Player A holds a gymnastic stick by its upper end in a vertical direction. Player B stands or kneels in front of him and holds his arm so that his forearm is bent in front of the body (90 degrees) and fingers are encircling the lower end of the stick, however, they are not touching it. When A drops the stick, B must catch it. On the stick there is marked a gauge in centimeters, which measures the level of reaction ability (change of execution - the opposite hand).

4. A couple of players, facing each other. Player A holds a ball in her arms stretched forward and suddenly drops it. The task of player B is to catch it before it touches the ground. 
5. A couple of players. Player A faces the wall in a 3-5 $\mathrm{m}$ distance. $\mathrm{B}$ throws a ball from behind player A onto the wall and player A tries to catch it and put it on the floor after a bounce from the wall. The game can be made more difficult by implementing more balls.

6. Couples of players in a queue, 5-8 m distance. On a signal of the trainer, back player throws the ball towards the teammate standing in the front of the queue. The front player attempts at turning round on a signal and catch the ball. Then the players change their positions.

7. Coach shouts body positions (e.g. sitting, lying at the back, kneeling, side lying, squatting, etc.) in a fast sequence. Players try to occupy the positions as fast as possible, to execute a jump up and return to the initial standing position.

8. Starts from various positions (sit, lying position, kneeling position, etc.) on a signal of a different character (audible, visual).

9. Player B stands $2 \mathrm{~m}$ behind player A. Player A, on a signal of the trainer, throws the ball to the right and left of the player B, who attempts at catching it after a turn sooner than it falls on the ground.

10. 5-6 players standing in a semi-circle (distances 4-5 m), each with a ball. They gradually throw the ball in a fast sequence to the player, who is standing in front of them in a distance of $6-8 \mathrm{~m}$. Her task is to catch/bounce back as many balls as possible. We can make the play more difficult by numbering the players. The coach shouts number of the player, who has to pass to the central player.

Main part - 65 minutes - contents: Acquisition of low position, overhand passing. Closing part - 5 minutes - contents: jogging, walking and deep breathing, conclusion of the reached results, motivation into further training work.

Training unit No. 2 ( $1^{\text {st }}$ year of training in a sport club):

Development of reaction speed

Tasks: Development of complex motor reaction ability

Duration of the unit: 90 minutes

Preparatory part - 20 minutes - contents: Selection of the exercises shown below:

1. Players freely move on the playground and on an acoustic signal they have to carry out a certain task (sit, 360 degrees turn, etc).

2. 5 gymnastic rings are situated on the floor of the volleyball playground and 6 jogging players move around it. On a signal, each player attempts at occupying a place in the ring. Player, who has not succeeded in it, is punished by 1 penalty point. The game continues until 10 points are scored or certain time elapses.

3. Two to four marked "fishermen" try to catch other players. If the fisherman touches any player, he must stop at a place with his legs spread apart. Free player can free him by passing through his legs wide apart.

4. Two players facing each other lay their arms on each other's shoulders. They try to step on the foot of the opponent. 
5. Two players facing each other, while being partitioned by a volleyball net. Player A does some activities by the net (squat, jump up, blocking, spiking, side gallop, etc.), player B tries to react as fast as possible and repeat the activity of player A.

6. Players A and B standing on baselines of the opposed sides of the playground. Player A has a ball and serves it over the net, player B tries to catch it before it touches the ground.

7. 5-6 players are standing freely on a half of the the playground with their backs towards the net. Player A, who is standing with balls on the other side of the net, serves the ball on a trainer's signal to the opponent, who attempts at catching/ bouncing the ball after a turn and start a rally.

8. Serving/playing around the net, which is hidden by a large piece of cloth.

9. Standing player A: feet slightly apart, arms stretched forward (ball on waist level). He throws up the ball hair high, claps his hands on his thighs (behind the body, touching the ground, repeatedly claps his hands in front of his waist, etc.) and catches the ball again at waist level. Organize a game, the winner is the most skilled player.

10. A couple of players standing with their backs together. A skipping rope is spread between their legs apart (handles of the rope are at feet level, between them). On a signal of the coach each player attempts at pulling the rope by its handles faster than the opponent.

Main part - 65 minutes - contents: Underhand passing drill, improvement of overhead passing.

Closing part - 5 minutes - contents: jogging, walking and deep breathing, conclusion of results reached, motivation into further training work.

Training unit No. 3 ( $2^{\text {nd }}$ year of training in a sport club):

Technical and tactical preparation.

Tasks: Improvement of passing accuracy (while standing and running-in).

Development of kinesthetic-differentiation ability of arms

Duration of the unit: 90 minutes

Preparatory part - 20 minutes - contents: Selection of the exercises:

Passing or throwing of balls of different size and weight (tennis, cricket, handball, volleyball balls) on a target at a distance of 3-6 m.

1. A trio of players with balls. Two of them (A and B) face each other at a distance of 6-8 m, player Cstandsin between. They pass/throw the ball quickly as to the pattern: B-A, A-C, C-B. After a certain time interval they exchange their positions. Repeat 15-20 times.

2. Players stand in a queue (2-3 m apart). Player A stands $3-5 \mathrm{~m}$ in front of the player $B$, in a queue, and she gradually exchanges a pass with all the players from the queue, while all move by one position. After a pass the player makes a squat.

3. The same as in drill 5 but with calling the numbers of players. All players are in 
a squat and the player, whose number the trainer shouts, stands up, receives the ball and passes it back to the central player.

4. A player passes the ball above and does a 90, 180, 360-degree turn.

5. A couple of players facing each other at a distance of 4-6 m. Player A passes the ball to player B, who, before passing the ball back, lays his ball down on the floor or passes it above his head. The action repeats.

6. Two teams try to pass the ball using an overhead pass into the circle at a distance of 6-8 m. The team, which reaches higher number of hits for a time interval, wins.

7. Basket-shooting. Two teams of equal number of players face their own basket at a distance of 4-6 m. Each player has a ball. The players, one by one, attempt at passing the ball to the basket.

8. Overhead passing while walking and pushing another ball with a leg.

9. A trio of players, one having a ball, stands in a triangle. Each has a medicine-ball on the floor at a distance of 2-3 $\mathrm{m}$ behind them. The player with the ball passes to the partner to the right, makes a start, touches his medicine-ball and quickly returns back to his initial position before he receives a pass from player 3. Passes should be performed so fast that the partner is not able to fulfil the task.

Main part - 65 minutes - contents: Improvement of passing accuracy while standing and running. Improvement of both handed underhand and overhand passing (stress on accuracy).

Closing part - 5 minutes - contents: trotting, walking and deep breathing, conclusions of the obtained results, motivation for further training work.

Individual kinds of sport preparation in the stage of initial specialization have different proportion:technical preparation (25\%), tactical preparation (18\%) and integral preparation-game (21\%). Table 6.17 presents the portion of individual kinds of sport preparation on the total volume of preparation in the period of initial sport specialization and in the period of specialized training.

We present model examples of microcycles with various contents part of which also includes the development of coordination abilities and improvement of technical skills.

\section{Example of a training unit in the microcycle in the 6th year of training process}

( $9^{\text {th }}$ week of preparatory period):

Tasks: Development of kinesthetic-differentiation ability

Duration of the unit: 90 minutes

Preparatory part - 30 minutes - contents: Selection of exercises:

1. Passing or throwing of balls of a different size and weight (tennis, cricket, basketball, volleyball, mini-volleyball, handball, small medicine-ball) onto a target from a distance of 3-9 meters.

2. Passing of balls to distant targets (e.g. gradually pass 5 balls with an effort to hit the full balls put in irregular distances). 


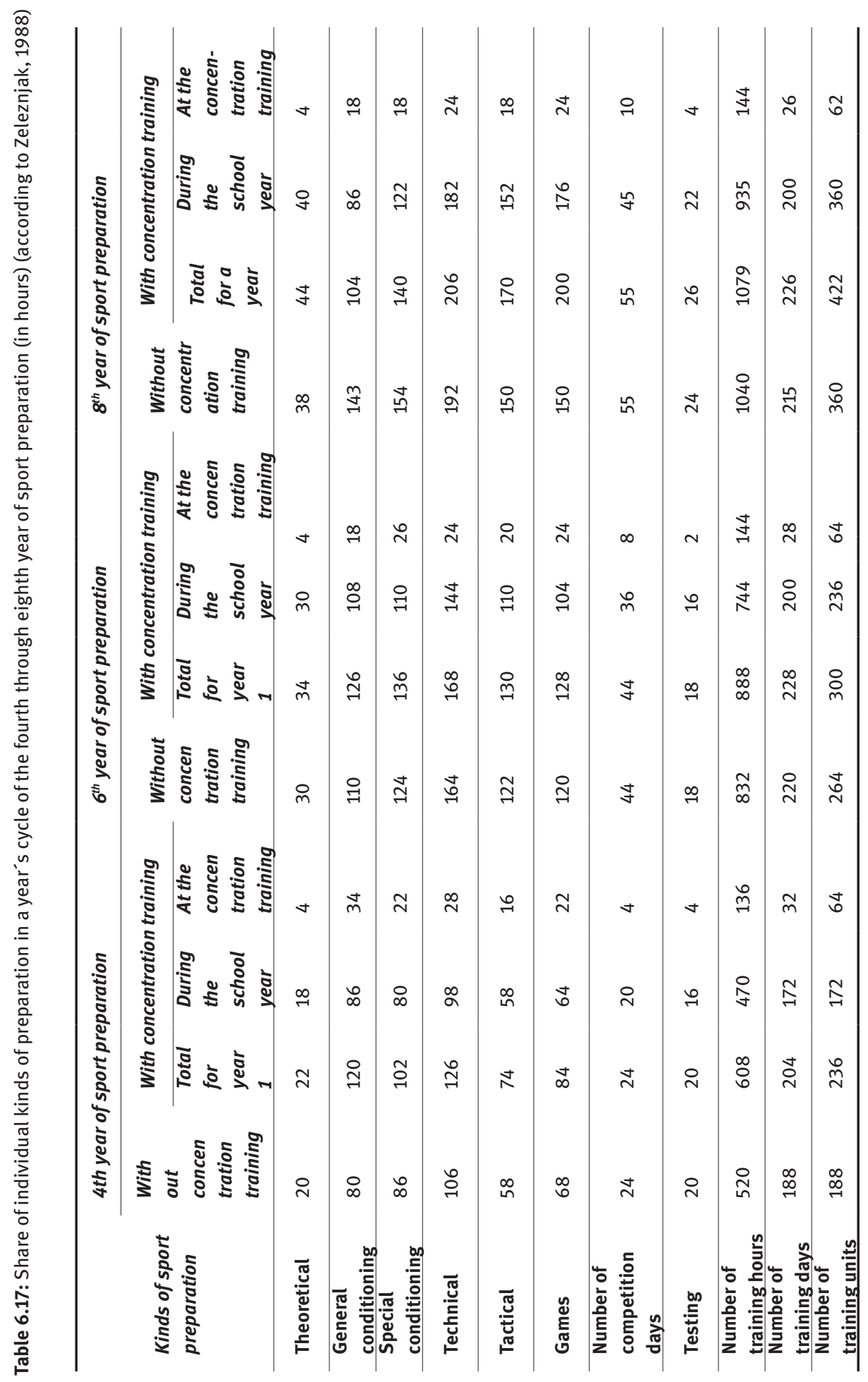


3. A trio of players with balls. Two players face each other at a distance of 10-12 $\mathrm{m}$, player $\mathrm{C}$ stands between them. They pass the ball quickly according to the pattern: B-A, A-C, C-B. After a certain time interval they exchange their positions. Repeat 15-20 times.

4. Passing the ball to the wall so that it falls, after rebounding, to a certain zone marked on the floor at a distance of 3-5 $\mathrm{m}$ from the wall.

5. Players stand in a queue ( $2-3 \mathrm{~m}$ behind each other). Player A stands $3-5 \mathrm{~m}$ in front of the queue and gradually exchanges a pass with the first through the last players, while all move one position. After a pass the player makes a squat.

6. The same as in drill 5 but with calling the numbers of players. All players are in a squat and the player, whose number the trainer shouts, stands up, receives the ball and passes it back to the central player.

7. Player A with a ball behind the basic line. Other players with a ball are situated irregularly on the playground (each in a different distance from player A). Player A gradually exchanges a pass with all players. Players shift by 1 position in the direction of watch hands.

8. Repeated both-legged leaps with landing into marked zones in various distances from each other.

9. Standing broad jums to a marked line at various distances $(200 \mathrm{~cm}, 210 \mathrm{~cm}$, $220 \mathrm{~cm})$.

10. Passing the ball overhead while standing and after a pass make a 90, 180 and 360-degree turn.

11. Squatting vaults over 5-6 obstacles of various heights (hurdles, gymnastic bucks, vaulting boxes pieces, benches, medicine-balls).

12. A couple facing each other standing at a distance of 6-8 $\mathrm{m}$. Player A passes to player B, who, before passing the ball back, lays his ball down on the floor or passes it above her head. The action repeats.

13. A couple of players standing at a distance of 6-9 m, each having a ball. They simultaneously pass the balls, while player B consistently changes his position (moves forward and backward). Players exchange their roles.

14. Two teams of equal number of players try to hit the circle situated on the floor at a distance of 10-15 m. Team, which gains more hits at a certain time interval, wins.

15. Basket-shooting. Two teams of equal number of players face their own basket at a distance of 4-6 m. Each player has a ball. The players, one by one, attempt at passing the ball to the basket.

16. Overhead passing in a circle with one player standing in the centre. Six players form a circle with a radius of 4-6 m. 7th player stands in the centre with three balls which she gradually passes to the game. Marking of players: A - central player, $\mathrm{B}, \mathrm{C}, \mathrm{D}, \mathrm{E}, \mathrm{F}, \mathrm{G}$ - players standing on the circumference of the circle. Ball trajectory: $A$ - pases the first ball to $B$, who passes it to $C$ and $C$ returns it back to $A$. A passes the second ball to $\mathrm{D}$ and $\mathrm{D}$ to $\mathrm{E}$ and $\mathrm{E}$ back to $\mathrm{A}$. A passes the third ball to player $\mathrm{F}$, who passes it to $G$ and $G$ back to $A$. Players attempt at realizing the passes as soon 
as possible so that the central player was under time pressure and could not catch all the three balls and put them on the floor.

17. Two players standing in queues facing each other at a distance of 5-7 $\mathrm{m}$. On a signal the first player of team A passes an overhead pass to the first player of team $B$ and runs to the end of the opponent queue. First player of team B passes the ball back to the first player of the opponent team and runs to the end of the opponent team. You can modify the distance of passing.

18. Repeated passing of the ball overhead while walking and at the same time pushing the ball with one leg (also in the form of a slalom between medicine-balls).

19. A couple standing on two benches standing one behind the other at a distance of 3-6 m. Overhead passing in a couple while players change their positions forward and backward.

20. Players form a circle with a radius of 3-5 m, each with a ball. In the centre, there stands one player without a ball. Players standing on the circle around her gradually pass their balls to her in order to put her under stress. Changing the centre player after a while.

21. A trio of players is standing in a triangle, one having a ball. Each of them has a medicine-ball on the floor at a distance of 2-3 $\mathrm{m}$ behind them. Player with a ball passes the partner to the right, makes a start, touches his medicine-ball and quickly returns back to his initial position before he receives a pass from player 3. Passes should be performed so fast that the partner was not able to fulfil the task.

22. Two players facing each other. Each of them has a ball. Overhead passing with two balls. Modification - playing with three balls.

23. Overhead passing with dark spectacles (with eyes half shut).

24. Lines are drawn on the wall in a different height (220, 230, 260, 280, 290, 305, $320 \mathrm{~cm}$ ). Player with a ball faces the wall at a distance of 2-4 meters. Passing the ball into the marked zones (coach shouts numbers of zones).

25. A horizontal line at the height of $220 \mathrm{~cm}$ is drawn into a corner of the gym (both left and right). Player with a ball faces the corner approx. at the distance of 2-3 m. He gradually passes the first ball to the right over the line and second ball to the left over the line.

26. Players stand with their side to the wall and facing each other. Overhead passing in couples so that the ball bounces from the wall (the basket).

27. Both legged splits over parts of the vaulting box situated on the ground, while player jumps into each of the component parts, which are spaced irregularly.

28. Mark 5 lines in various heights on the wall. Repeated jumping with reaching the lines with numbers shouted by the trainer.

Some drills for athletic adults and youngsters to consider when they desire to improve hand eye coordination for the sake of sports performance (according to Rousseau, 2013): 
29. Connect Four: Connect Four is a game of visual planning and organization. The hand part of hand eye coordination won't get much of a workout. However, the eye part will and that can't hurt.

30. Focus near and far: Quickly practice focusing on a near and then a far object. Go back and forth, back and forth.

31. Have someone try to throw a soft ball (like a nerf ball) by you into a real or makeshift goal. The only catch? You have to stop the ball with your hands. Depending on your performance, have the thrower move closer or further away.

32. Have a catch with a catch: Get a large wiffle ball, softball, or really any ball that's light colored. Then write a bunch of letters on the ball with a black marker. Next, find someone to have a catch with. As each of you is about to catch the ball, call out the last letter you see.

33. Have a catch with yourself: One thing you can do to improve hand eye coordination is throw a baseball up in the air repeatedly and catch it. The same goes for any ball, including a football.

34. Raquet sports: Try playing as many raquet sports as possible. Ever play ping pong? Well, if you have then you know how much that sport can improve your hand eye coordination. Have to assume that raquetball is of the same ilk. Tennis too. In other words, anytime you have to react to another person's movement and a ball with your own hand, you're going to improve hand eye coordination.

35. Speed bag drills: Boxers have outstanding hand eye coordination simply because if they didn't they'd be unconscious a lot of the time. One thing they do to keep sharp is use the speed bag.

36. Video games: Chris Spielman, an outstanding former linebacker for the Detroit Lions, once indicated that he sometimes would work on hand eye coordination via video games. How often this occurred is unclear. What we do know is that visual perception and motor skills can be improved through the use of video games.

37. Wall ball: Stand in front of a flat wall with a basketball. Then begin to throw it against the wall and catch it. After you've warmed up sufficiently, begin to throw it against the wall with only one hand. Every time it bounces off the wall push it back against the wall - without catching it - with the fingertips of the same hand you threw it with. Then repeat with your non-dominant hand.

\section{Example of a training unit in the microcycle in the sixth year of training} process

(20 ${ }^{\text {th }}$ week of competition period)

Tasks: Development of space-orientation ability

Duration of the unit: 90 minutes

Preparatory part - 30 minutes - contents: Selection of the following exercises:

1. Playing over the net with a smaller/larger number of players with two balls at once.

2. 6 players stand with their backs to the net in low stance on a volleball field. On a signal player A standing behind the base line of the opponent's ground serves 
the ball. Players in the field react to the signal, make a $180^{\circ}$ turn, catch the ball and realize an attacking combination according to the number the coach shouts. Position of players in the field is changing after several serves.

3. Team stands in a queue and in front of the first player there is a mat. Player A with a ball stands opposite her team approx. 4-5 m from it. First player of the team makes a front roll, passes the ball to player A, and replaces her. Player A runs to the end of the queue. All players from the queue gradually exchange themselves.

4. Hunting game on a small field with a large number of players and several marked hunters.

5. Players spike a ball to the floor so that it bounced from the wall above them in order to spike again. Repeat 15-20 times in two to three series.

6. Player passes the ball high above his head and after each pass he makes a 180 (360 degree) turn. 3 series 10 passes each.

7. Overhead passing in couples and after each pass the players make a 180-360 degree turn or squat, kneel, sit, lying position.

8. Overhead passing in couples at various distances and later also with more balls.

9. Exercises in trios. Player in the centre makes a turn to player A or B and passes underhand or overhand pass.

10. The same as in drill 9 but the player in the centre passes the ball in turns after a front roll (player A) and a back roll (player B).

11. Two teams (A and B) are freely spaced on each half of the playground, while each player of team A has a ball. Players move freely around the playground while passing their balls above their heads. Each player of team A has a partner in team B. On a signal players of team A quickly orientate themselves and pass the ball to their partner at the other side of the net, who continues in overhead passing while moving. Repeat 10 times.

12. Two players facing, each at the playground's width. They pass the ball repeatedly while galloping sideways. After a pass they carry out a 360 degree turn.

13. Players stand in two queues facing each other. On a signal the first player of team A passes an overhead pass to the first player of team $B$ and runs to the end of the opponent queue. First player of team B passes the ball back to the first player of the opponent team and runs to the end of the opponent team. You can modify the distance of passing.

14. A team stands in a queue behind the base line. In front of these players 3 mats in a row are situated at the distance of $3 \mathrm{~m}$, behind them there are 3 balls on the floor. Setter $B$ stands at a distance of 6-9 $\mathrm{m}$ from the balls. On a signal, the first player (A) of the team starts forward, makes 3-4 front rolls (back rolls, alternatively, front and back), takes one ball and passes it to the setter B, who catches it and puts it on the floor. Player A runs back to the base line, touches it and repeats rolls and passes the ball to the setter until all 4 balls have been passed. Relay continues with other players (team`s game).

15. Players with numbers $1-5$ stand in a circle around the player 6 (stands in the centre). On a signal player 6 passes the ball to the player with the ball shouted 
by the coach(eg. 1,4,3,1,2). Player in the circle passes the ball back to the central player.

16. Six players with balls stand in a circle with a radius of $3 \mathrm{~m}$. On a signal, they pass the ball above head and pass it to the player standing on the right. They peripherally watch other balls so as one player has not got two balls at once.

17. Team in a queue behind the base line. 5-6 numbered players are freely spaced on the ground. Player A occupies a low stance at a distance of 2-3 $\mathrm{m}$ in front of the line. He receives gradually fast passes from the players in the queue and passes to the plyer on the ground, whose number is shouted by the coach. After a certain number of passes players exchange their roles.

18. Circuit training, where a player makes alternatively various activities like overhead pass and front roll (back roll, cartwheel, a 180 degree turn, jump up for blocking, back dive, front dive).

In the stage of top sport preparation, we expect satisfactorily developed mastery in players, which is based on a high level of coordination abilities. It is manifested by a virtuous, athletic acquisition of skills by an individual as well as in cooperation in a game. A characteristic sign is effectiveness of individual game situations in individual matches in volleyball. Coordination preparation is focused on improving the quality of the level of special coordination abilities, which are tweaked in the process of technical improvement (Tab. 6.18). We provide an example of a microcycle in the tenth year of sport preparation (Tab. 6.19).

Table 6.18: Share of individual kinds of preparation in a year's cycle of the nineth to eleventh year of sport preparation (in hours) (according to Zeleznjak, 1988)

\begin{tabular}{llll}
\hline \multirow{2}{*}{ Kinds of sport preparation } & \multicolumn{3}{l}{ Year of training preparation } \\
\cline { 2 - 4 } & 9. & 10. & 11. \\
\hline Theoretical & 46 & 50 & 60 \\
\hline General conditioning & 110 & 110 & 130 \\
\hline Special conditioning & 140 & 140 & 180 \\
\hline Technical & 200 & 245 & 260 \\
\hline Tactical & 200 & 200 & 250 \\
\hline Games & 208 & 242 & 290 \\
\hline Testing & 30 & 32 & 36 \\
\hline Number of training hours: & 1144 & 1248 & 1456 \\
\hline - $\quad$ number of training days & 258 & 276 & 276 \\
\hline$\quad$ number of training units & 374 & 398 & 408 \\
\hline - $\quad$ number of working days & 60 & 65 & 70 \\
\hline
\end{tabular}


Table 6.19: Example of a microcycle in the tenth year of sport preparation (second stage of preparatory period)

Day Contents of sport preparation

Morning: Development of coordination abilities and strength. Exercises should be focused on the development of

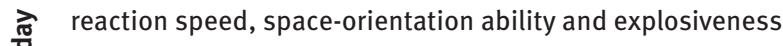

(rope-skipping and obstacle leaping).

$\sum$ Afternoon: Development of speed abilities - sprinting exercises, starts from various positions, stretching

产

\section{Load proportioning}

20 min. Gymnastic exercises

6-7 exercises, $3-4 \times 10$ for each coordination ability $10 \times 10 \mathrm{~m}$ from low start, 20 repetitions of reaction exercises 600-800 m run, warm-up, $3 \times 600 \mathrm{~m}$ tempo run

Morning: Development of coordination and strength $20 \mathrm{~min}$. Sport game, $15 \mathrm{~min}$. abilities. Coordination exercises focused on the development Gymnastic warm-up, of space-orientation and kinesthetic-differentiation sbility. Plyometry. Stretching. $5 \times 10$ repetitions for each coordination ability. Afternoon: Development of speed abilities and endurance in explosiveness. Game - football, basketball, „debla“. 6-8 exercises $2 \times 10$ repetitions each, 10-15 $\mathrm{min}$. Game.

Morning: Development of coordination abilities with the 6-8 exercises $3 \times 10$

focus on kinesthetic-differentiation ability. repetitions for each Game: 3-3, 4-4. Flexibility and compensation exercises. coordination ability. $30 \mathrm{~min}$.

Morning: Development of coordination and strength abilities. Focus: kinesthetic-differentiation and spaceorientation ability. Strength exercises - circular form.

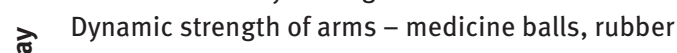
은 expanders - contrast method.

Afternoon: Development of speed frequency and reaction speed. Reaction exercises with the change of direction of the movement. Flexibility and compensation exercises.

\begin{tabular}{ll} 
& $15 \mathrm{~min}$. \\
\hline Development of aerobic endurance - continuous steady & $20-30 \mathrm{~min}$. \\
i⿱ &
\end{tabular}

10-15 min. Gymnastic warmup 6-8 exercises $3 \times 10$ repetitions each 25 min. 8-10 stands - 10-15 repetitions $30 \mathrm{~min}$.

$15 \mathrm{~min}$. 